Clinical Image

\section{Opera-glass hand with arthritis mutilans in psoriatic arthritis}

\author{
Gautam Mullick ${ }^{1 *}$, Ajay Handa and Vikas Chauhan ${ }^{3}$ \\ ${ }^{1}$ Department of Rheumatology, MD, DNB, INHS ASVINI, Mumbai, India \\ ${ }^{2}$ Department of Pulmonary Medicine, MD, DM, INHS ASVINI, Mumbai, India \\ ${ }^{3}$ Department of Radiology, MD, INHS ASVINI, Mumbai, India
}

\section{Clinical image}

A 42 years old gentleman who was a known case of Psoriasis vulgaris since last 5 years presented to the Rheumatology clinic with inflammatory arthritis predominantly involving the joints of the upper extremities. Musculoskeletal examination of both hands revealed dactylitis and distal interphalangeal joint arthritis. He had a shortened right ring finger with excessive transverse skin folding suggestive of an Opera-Glass hand (Figure 1A). A Radiograph of the same revealed arthritis mutilans with complete resorption of the middle phalanx (Figure 1B).

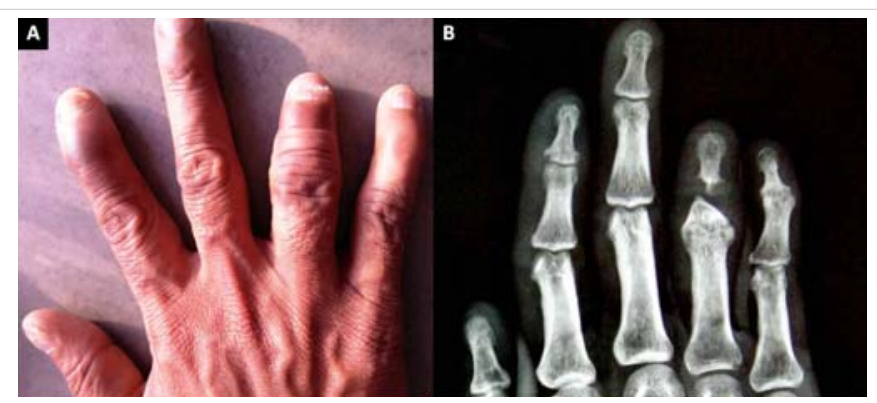

Figure 1: Opera-Glass hand (A) and arthritis mutilans with complete resorption of middle phalanx (B) in a patient of psoriatic arthritis.

\section{More Information}

*Address for Correspondence: Gautam Mullick, Department of Rheumatology, MD, DNB, INHS ASVINI, Mumbai, India, Tel: 8800540270 ; Email: gautammullick@yahoo.com

Submitted: 22 May 2020

Approved: 27 May 2020

Published: 28 May 2020

How to cite this article: Mullick G, Handa A, Chauhan V. Opera-glass hand with arthritis mutilans in psoriatic arthritis. J Clin Med Exp Images. 2020; 4: 002-002.

DOI: 10.29328/journal.jcmei.1001015

Copyright: @ 2020 Mullick G, et al. This is an open access article distributed under the Creative Commons Attribution License, which permits unrestricted use, distribution, and reproduction in any medium, provided the original work is properly cited.

A) Check for updates

OPEN ACCESS 